\title{
Echocardiographic and Clinical Correlates of Ejection Fraction Among 2000 Patients with Heart Failure in Western Saudi Arabia
}

This article was published in the following Dove Press journal: International Journal of General Medicine

\begin{abstract}
Ahmed Hussein Subki, (D) Mohammed Ali Almalki, (iD) ${ }^{2}$ Nadeem Shafique Butt, (D) ${ }^{3}$ Mohammed Saad Alsallum, (iD ${ }^{4}$ Hatim Mashan Almutairi, (D) 5 Hazim Abdulkarim Khatib, (D) ${ }^{6}$ Abdulrahman Mousa Alzahrani, ${ }^{6}$ Abdullah Salem Babaker, (D) ${ }^{6}$ Firas Abdulrahman Addas, iD ${ }^{6}$ Abdullah Abdulfattah Mashat, (iD) ${ }^{7}$ Ammar Yasser Jad, (iD ${ }^{6}$ Zohair Abdulwahab Zafar, ${ }^{6}$ Baraa Waleed Nogali, ${ }^{6}$

Abdulaziz Abdulsalam

Alghamdi, (iD) ${ }^{6}$ Nasser Adel Alghamdi, (iD ${ }^{6}$ Mohanad Fahad Dakhakhni, iD ${ }^{6}$ Omar Tamer Asaad, ${ }^{6}$ Kamal Waheeb Alghalayini (iD) ${ }^{6}$

'Department of Internal Medicine, King Faisal Specialist Hospital and Research Centre, Jeddah, Saudi Arabia; ${ }^{2}$ Department of Internal Medicine, King Faisal Medical Complex, Taif, Saudi Arabia; ${ }^{3}$ Department of Biostatistics, King Abdulaziz University, Jeddah, Saudi Arabia; ${ }^{4}$ Department of Neurology, King Abdulaziz Medical City, Jeddah, Saudi Arabia; ${ }^{5}$ Department of Radiology, Prince Mohammed Bin Abdulaziz Hospital, Riyadh, Saudi Arabia; ${ }^{6}$ Department of Internal Medicine, College of Medicine, King Abdulaziz University, Jeddah, Saudi Arabia; ${ }^{7}$ Department of Surgery, College of Medicine, King Abdulaziz University, Jeddah, Saudi Arabia
\end{abstract}

Correspondence: Kamal Waheeb Alghalayini

Department of Internal Medicine,College of Medicine, King Abdulaziz University, Jeddah, Saudi Arabia

Tel +966-12-6408222 ext 18244-18272

Email kalghalayini@kau.edu.sa
Introduction: Heart failure (HF) affects about 320,000 Saudi individuals and is associated with a considerable negative impact on the patients' quality of life. In literature, there is a lack of data about the echocardiographic abnormalities of HF patients in Saudi Arabia.

Aim of Work: To describe the echocardiographic findings of HF patients in Western Saudi Arabia.

Methodology: This was a retrospective record review study conducted on 2000 patients with chronic HF in Saudi Arabia. Demographic, clinical and echocardiographic data were collected and compared among patients with $\mathrm{HF}$ with reduced ejection fraction (HFrEF), ie, $\mathrm{EF} \leq 40 \%$; $\mathrm{HF}$ with mid-range $\mathrm{EF}$ (HFmrEF), ie, $\mathrm{EF}=41-49 \%$; and $\mathrm{HF}$ with preserved $\mathrm{EF}$ (HFpEF), ie, $\mathrm{EF} \geq 50 \%$.

Results: Among the 2000 patients studied, females constituted $46.3 \%$ of the sample. About $52 \%$ of females had HFpEF, whilst $70 \%$ of males had HFrEF $(\mathrm{p}<0.0001)$. Diastolic dysfunction occurred in $98 \%$ of HFpEF versus $78 \%$ of HFrEF $(\mathrm{p}<0.0001)$. Patients with HFrEF had higher left-ventricular diastolic (LVd) volume (1536 versus 826), higher left-ventricular systolic (LVs) volume (1660 vs 772), higher left atrial volume (1344 vs 875), higher aortic root dimension (1144 vs 929) and lower fractional shortening (FS) (267 vs 1213) than patients with HFpEF $(\mathrm{p}<0.0001)$.

Conclusion: HFpEF was more common among females and was associated with higher rates of diastolic dysfunction and higher FS. HFrEF was prevalent among males and associated with higher LVd, LVs, left atrium volume and aortic root dimensions.

Keywords: echocardiography, heart failure, Saudi Arabia, ejection fraction, HFpEF, HFmrEF, HFrEF

\section{Introduction}

Heart failure (HF) is the leading cause of cardiovascular morbidity and mortality worldwide. ${ }^{1}$ It is estimated that HF affects about $1-2 \%$ of the adult population, and the prevalence increases to $10 \%$ among individuals above the age of 70 years. $^{2,3}$ In developed countries, more than one million hospitalizations are attributed to HF, and the five-year mortality rate is estimated to be as high as $50 \%$. Moreover, the burden of HF is anticipated to increase during the coming decades, due to the expanding pool of surviving patients and the growing elderly population. ${ }^{4}$ About 5 million individuals are diagnosed with HF worldwide, and the numbers are expected to increase by approximately 550,000 annually. ${ }^{3}$

Left-ventricular dysfunction is the initial pathophysiologic step in $\mathrm{HF}^{5}$ It results from an insult to the myocardium (eg, ischemia) that leads to reduced systemic 
perfusion and systemic venous congestion. ${ }^{6}$ The myocardium responds by remodeling and hypertrophy which, in turn, exacerbates the myocardial stress and results in mitral regurgitation. ${ }^{5}$ The diagnosis of HF is complex. ${ }^{7}$ Clinically, it is based on the patient's symptoms and clinical signs, which are sometimes non-specific, very subtle, or even absent. Less than $25 \%$ of the cases can be diagnosed clinically. ${ }^{8}$ Recent HF guidelines assert specific insights to detect subclinical left ventricular and diastolic dysfunction before the onset of symptoms. Though the standard physical examination can detect some signs of $\mathrm{HF}$, the signs are seldom overt until advanced stages of $\mathrm{HF}$, also, an accurate estimation of the cardiac output state and volume cannot be made solely based on clinical assessment. ${ }^{9,10}$ Echocardiography is the most appropriate diagnostic test for the initial assessment of HF patients, as recommended by the American College of Cardiology/ American Heart Association guidelines for the diagnosis and management of HF. ${ }^{11,12}$ Echocardiography can evaluate the diastolic function, left-ventricular end-diastolic pressure and left atrial pressure, and demonstrate the morphologic, structural, functional and hemodynamic changes in HF, which give a clue for determining the etiology of the condition. ${ }^{13}$

Data about the prevalence, etiology, risk factors, diagnosis, and management of HF in the Middle East are scarce. ${ }^{14-19}$ About 320,000 individuals are being treated for HF in Saudi Arabia, ${ }^{17}$ and the etiological and risk factors for HF in Saudi Arabia are closely similar to those reported in western countries. ${ }^{20,21}$ There is a lack of data, however, on the echocardiographic findings of HF patients in Saudi Arabia. Hence, the main aim of this study was to examine and describe the echocardiographic findings of a sample of HF patients in Western Saudi Arabia.

\section{Methodology}

\section{Study Design and Population}

This was a retrospective record review study conducted on 2000 patients diagnosed with HF who were admitted at the King Abdulaziz University Hospital in Jeddah, Saudi Arabia during the years 2016 to 2018. All adult patients diagnosed with HF, based on both clinical and echocardiographic criteria, were eligible for recruitment to this study. ${ }^{22,23}$ Inclusion criteria included adult patients $(\geq 18$ years), both genders, any nationality, and chronic HF diagnosed based on the Framingham criteria for the diagnosis of HF. ${ }^{22}$ Patients with acute HF and pediatric patients were excluded from this study.

\section{Data Collection Procedure}

The data were collected from the patients' records at the hospital. Both demographic data (ie, age, sex, and race), clinical data (ie, in-hospital mortality) and echocardiographic data (ie, ejection fraction (EF), left-ventricular diastolic volume (LVd), left-ventricular systolic volume (LVs), FS, left atrium volume, aortic root dimension and the existence of diastolic dysfunction) were collected. King Abdulaziz University Hospital granted access to the data for this study. All echocardiographic reports in our facility are written and/or approved by a cardiology consultant with echocardiographic experience. Diastolic dysfunction assessments were primarily made based on measurements in relation to mitral inflow, tissue doppler on the septum and lateral wall, pulmonary venous flow, and tricuspid velocity.

\section{Statistical Analysis}

Analysis of data was based mainly on the EF categories of the patients. All patients were divided according to their EF into three categories: patients with $\mathrm{EF} \leq 40 \%$, patients with EF between $41 \%$ and $49 \%$, and patients with $\mathrm{EF}$ $\geq 50 \%$. The distribution of EF was studied among the patients' demographic, clinical, and echocardiographic data. The impact of different variables on EF was also studied to determine which of them predicts the EF value.

All gathered data were fed into a computer, and analyzed using the IBM SPSS software version 20.0. ${ }^{24,25}$ Approximately $2.5 \%$ of data were missing. Categorical variables were expressed as frequency and percentages, while quantitative variables were presented as mean, standard deviation (SD) and mean ranks. The chi-square test of independence was conducted to explore the association of EF categories with various demographic and clinical factors. The Kruskal Wallis rank-sum test was conducted to examine the difference in mean ranks of various echocardiography variables with EF; differences in mean ranks were also presented with box-plots. Ordinal logistic regression was conducted to examine which demographic and echocardiographic variables had a significant effect on EF. The multivariate analysis Chi-Squared Automatic Interaction Detection (CHAID) classification algorithm was used to create a decision tree to select the most relevant covariate to predict the $\mathrm{EF}$ and to determine important cutoffs of significant predictors. 


\section{Ethical Considerations}

All data collected from the patients' records were anonymous. On hospital admission, all patients sign a written informed consent that they agree to the use of their recorded data (anonymously and confidentially) for research purposes. A copy of these consents was taken, and the ethical committee of King Abdulaziz University, Jeddah, Saudi Arabia approved this study.

\section{Results}

Among the 2000 patients studied, Saudi individuals constituted $43.5 \%$ of the cases. The remaining patients were of different nationalities, including Pakistani, Yemeni, Sudanese, Palestinian, Philippine, and Mauritian. Females constituted $46.3 \% \quad(n=925)$ of the recruited sample.

On studying the distribution of EF categories among the studied patients according to their demographics, there were significant differences according to patients' gender and diastolic dysfunction. Males constituted the vast majority of patients with $\mathrm{EF}$ of $40 \%$ or less and EF between $41 \%$ and $49 \%$ (70.1\% and $63.5 \%$, respectively), whereas females constituted more than half of the patients $(52 \%)$ with $E F \geq 50 \%(p<0.0001)$. Similarly, the number of patients with diastolic dysfunction was significantly higher than those without diastolic dysfunction in all categories of EF (78\% of patients with $\mathrm{EF} \leq 40 \%, 82.5 \%$ of patients with $41-49 \%$ and $97.9 \%$ of patients with $E F \geq 50 \%, p<0.0001)$. The detailed description of EF category distribution among patients according to their demographics, clinical and diastolic dysfunction is depicted in Table 1.

Concerning the echocardiographic findings, there was a significant association between the EF categories and all studied echocardiographic parameters (Table 2). It was noted that higher LVd (1536), higher LVs (1660), higher left atrium volume (1344), and higher aortic root dimensions (1144) were encountered among patients with $\mathrm{EF} \leq 40 \%(\mathrm{p}<0.0001)$. In contrast, lower FS (267.35) was associated with $E F \leq 40 \%(p<0.0001)$. Figure 1 demonstrates the differences in LVd, LVs, FS, left atrium volume, and aortic root dimensions among different EF categories.

To study the odds of different demographic, clinical, and echocardiographic variables for determining the EF category, an ordinal logistic analysis was conducted. The model was evaluated based on an alpha of 0.05 . The results of the model were significant $(\chi 2=1314.27$, $\mathrm{p}<0.001)$. McFadden's R-squared was calculated to examine the model fit, where values greater than 2 were indicative of models with excellent fit. $^{26}$ The McFadden $\mathrm{R}$-squared value calculated for this model was 0.48 . The regression coefficient for $\mathrm{LVd}$ was significant $(\mathrm{B}=-0.99$, $\left.\chi^{2}=62.66, \mathrm{p}<0.001\right)$, suggesting that a one-unit increase in LVd would decrease the odds of observing a higher category of EF by $62.91 \%$. Similarly, the regression coefficient for $\mathrm{FS}$ was significant $(\mathrm{B}=0.16, \chi 2=292.69, \mathrm{p}$ $<0.001$ ), suggesting that a one-unit increase in FS would increase the odds of observing a higher category of EF by

Table I Distribution of Ejection Fraction Categories Among HF Patients in Saudi Arabia According to Their Nationality, Sex, Associated in-Hospital Mortality and Diastolic Dysfunction $(n=2000)$

\begin{tabular}{|c|c|c|c|c|c|c|c|c|}
\hline & & Ejec & raction & & & & & P-value \\
\hline & & $\leq 40 \%$ & & $41-$ & & $\geq \mathbf{5 0} \%$ & & \\
\hline & & $\mathbf{n}$ & (\%) & $\mathbf{n}$ & (\%) & $\mathbf{n}$ & (\%) & \\
\hline Nationality & Saudi & 168 & $(42.0)$ & 49 & $(39.2)$ & 653 & $(45.2)$ & 0.274 \\
\hline & Non-Saudi & 232 & $(58.0)$ & 76 & $(60.8)$ & 793 & $(54.8)$ & \\
\hline Sex & $\mathrm{F}$ & 120 & $(29.9)$ & 46 & $(36.5)$ & 759 & $(52.0)$ & $0.000 *$ \\
\hline & M & 281 & $(70.1)$ & 80 & $(63.5)$ & 701 & $(48.0)$ & \\
\hline In-Hospital mortality & No & 379 & $(94.5)$ & 122 & $(96.8)$ & 1409 & (96.5) & 0.171 \\
\hline & Yes & 22 & $(5.5)$ & 4 & $(3.2)$ & 51 & $(3.5)$ & \\
\hline Diastolic Dysfunction & No & 88 & $(22.0)$ & 22 & $(17.5)$ & 31 & $(2.1)$ & $0.000 *$ \\
\hline & Yes & 312 & $(78.0)$ & 104 & $(82.5)$ & 1427 & (97.9) & \\
\hline
\end{tabular}

Note: *Statistically significant.

Abbreviations: $\mathrm{N}$, number; HF, heart failure. 
Table 2 Distribution of Ejection Fraction Categories According to Different Echocardiographic Findings Among the Studied Patients $(n=2000)$

\begin{tabular}{|c|c|c|c|c|}
\hline & EF (\%) & $\mathbf{n}$ & Mean Rank & P-value \\
\hline LVd & $\begin{array}{l}\leq 40 \% \\
41-49 \% \\
\geq 50 \%\end{array}$ & $\begin{array}{l}398 \\
126 \\
1455\end{array}$ & $\begin{array}{l}1536.54 \\
1 \mid 46.08 \\
826.98\end{array}$ & $0.000 *$ \\
\hline LVs & $\begin{array}{l}\leq 40 \% \\
41-49 \% \\
\geq 50 \%\end{array}$ & $\begin{array}{l}398 \\
126 \\
1455\end{array}$ & $\begin{array}{l}1660.32 \\
1388.51 \\
772.13\end{array}$ & $0.000 *$ \\
\hline FS & $\begin{array}{l}\leq 40 \% \\
41-49 \% \\
\geq 50 \%\end{array}$ & $\begin{array}{l}392 \\
122 \\
1447\end{array}$ & $\begin{array}{l}267.35 \\
511.52 \\
1213.91\end{array}$ & $0.000 *$ \\
\hline Left Atrium & $\begin{array}{l}\leq 40 \% \\
41-49 \% \\
\geq 50 \%\end{array}$ & $\begin{array}{l}391 \\
125 \\
1447\end{array}$ & $\begin{array}{l}1344.03 \\
1082.66 \\
875.48\end{array}$ & $0.000 *$ \\
\hline Aortic Root & $\begin{array}{l}\leq 40 \% \\
41-49 \% \\
\geq 50 \%\end{array}$ & $\begin{array}{l}388 \\
125 \\
1440\end{array}$ & $\begin{array}{l}1144.25 \\
1002.65 \\
929.71\end{array}$ & $0.000 *$ \\
\hline
\end{tabular}

Note: *Statistically significant.

Abbreviations: EF, ejection fraction; FS, fractional shortening; LVd, left-ventricular diastolic dimension; LVs, left-ventricular systolic dimension, n, number.

$16.96 \%$. The remaining studied variables were insignificant (Table 3 ).

The Chi-Squared Automatic Interaction Detection classification algorithm was used to create a decision tree to select the most relevant covariate to predict EF. Nationality, sex, inhospital mortality, along with echocardiography variables (LVd, LVs, FS, left atrium volume, aortic root dimension, and diastolic dysfunction) were selected as input variables. LVs were found to be the most important and significant factor $\quad($ Chi-Squared=1345.39, $\quad \mathrm{df}=10, \quad \mathrm{P}$-value=0.000): 97.5\% of the cases with $\mathrm{EF} \geq 50$ were observed to have an LVs of $\leq 2.77$ (Node 1 ), whilst only $2 \%$ of cases with $E F \geq 50$ were found to have an LVs more than 4.62 (Node 6). Along with LVs, left atrium volume was also found to be significantly associated with EF in the LVs " $\leq 2.77$ " subgroup (ChiSquare $=26.32, \mathrm{df}=4, \mathrm{P}$-value $=0.003$ ): $99.2 \%$ of the cases with $\mathrm{EF} \geq 50$ were found to have a left atrium volume of 3.72 or less (Node 7). In the subgroup of patients with LVs between 3.19 and 3.6, LVd was noted to be significantly associated with $\mathrm{EF}$ (Chi-Square=64.3, $\mathrm{df}=2$, $\mathrm{P}$-value $=0.000$ ), ie, $92.7 \%$ of cases with $\mathrm{EF} \geq 50$ were found to have an LVd of 4.79 or more (Node 11). In the subgroup of patients with LVs between 3.6 and 3.92, FS was significantly associated with $\mathrm{EF}$ (Chi-Square $=78.6, \mathrm{df}=2, \mathrm{P}$-value $=0.000$ ): 93.5\% of cases with $\mathrm{EF} \geq 50$ were found to have an $\mathrm{FS}>26.5$
(Node 13). In the subgroup of patients with LVs between 3.19 and 3.60 and LVd more than 4.79, a significant association was noted between FS and EF (Chi-Square $=29.59, \mathrm{df}=2$, $\mathrm{P}$-value $=0.000$ ). About $99 \%$ of patients with $\mathrm{EF} \geq 50$ were noted to have an FS of more than 32.3. The remaining studied variables (ie, sex, nationality, in-hospital mortality, aortic root dimension, diastolic dysfunction) were insignificant (Figure 2).

\section{Discussion}

Patients with HF are categorized according to their ejection fraction into patients with $\mathrm{HF}$ with reduced $\mathrm{EF}$ (HFrEF), ie, $\mathrm{EF} \leq 40 \%$, patients with $\mathrm{HF}$ and mid-range $\mathrm{EF}$ (HFmrEF), ie, EF between $41 \%$ and $49 \%$ and patients with $\mathrm{HF}$ and preserved $\mathrm{EF}, \mathrm{ie}, \mathrm{EF} \geq 50 \%$ (HFpEF). ${ }^{27,28}$ This classification was proposed by the European society of cardiology (ESC) for the determination of the etiology of $\mathrm{HF}$ and for deciding the best treatment modality for different patients. ${ }^{11,28}$ In this study, echocardiographic findings were studied in 2000 patients with HF in Saudi Arabia. The findings were studied in correlation with different clinical and demographic variables.

In terms of gender, females recruited to this study were more likely to have HFpEF, whereas males were more likely to have HFmrEF or HFrEF. This is in accordance with data from reported literature, where HFpEF was more commonly encountered among females than males. ${ }^{29}$ The results of previous studies demonstrated that HF among females is more likely to be caused by atrial fibrillation and hypertension, whilst the main cause of HF among males is ischemic heart disease. ${ }^{29-34}$

Diastolic dysfunction was more prevalent among patients with HFpEF. In accordance with what was reported in the literature, patients with HFpEF are more likely to have diastolic dysfunction than patients with HFrEF owing to the pathophysiology of the HF. ${ }^{35,36}$ From the pathophysiology point of view, HFpEF is a disease of diastolic dysfunction. ${ }^{36,37}$ It manifests with raised end-diastolic pressure, raised left atrial filling pressure, increased myocardial wall stiffness and increased left atrial filling pressure, alteration in the preload, alteration in the end-diastolic volume and decreased elasticity and recoil of the myocardial vasculature. ${ }^{38}$ Patients with HFpEF have more extensive perivascular fibrosis, more collagen crosslinking, more fibrotic signaling (eg tissue growth factor-beta 1), and more left-ventricular stiffness than patients with HFrEF. ${ }^{39}$ This explains our findings. 
A

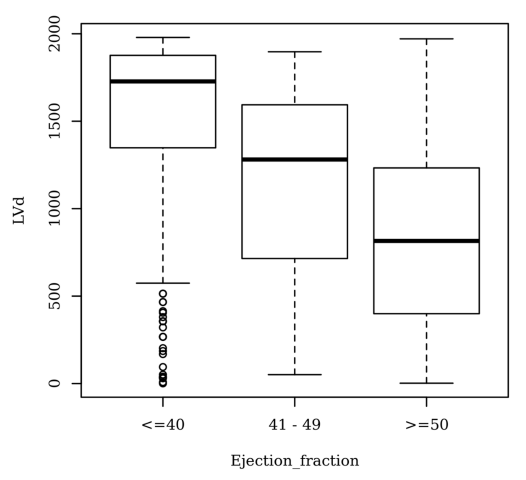

B

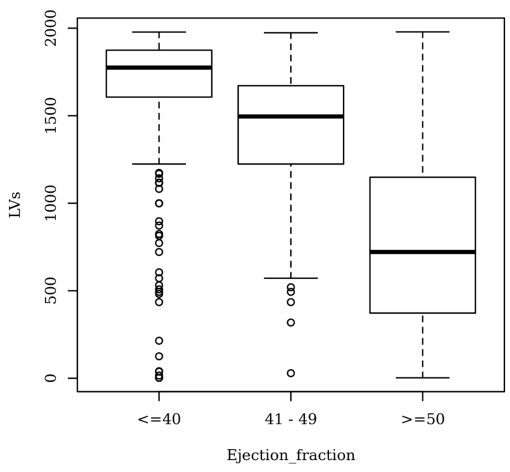

C

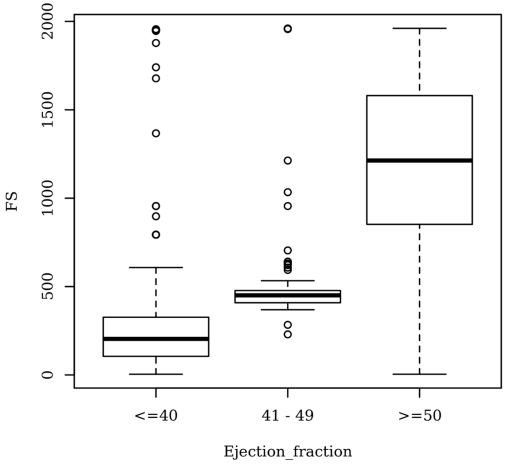

D

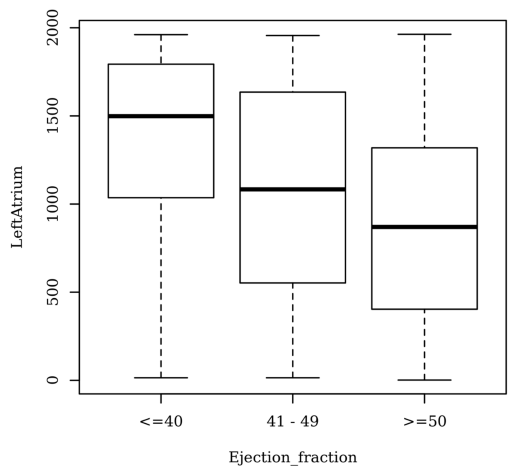

E

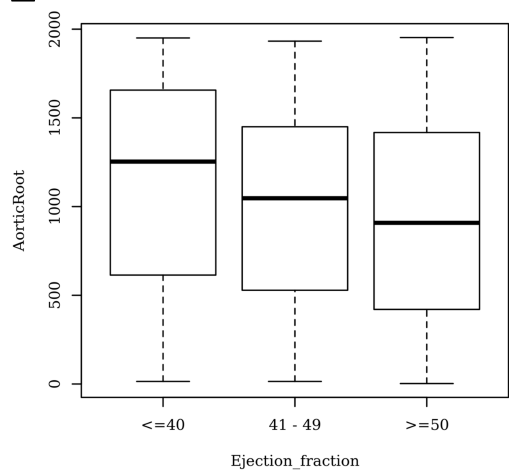

Figure I The differences in LVd (A), LVs (B), FS (C), left atrium volume (D) and aortic root dimensions (E) among the different ejection fraction categories in the studied patients $(n=2000)$.

Abbreviations: LVd, left-ventricular diastolic volume; LVs, left ventricular systolic volume; FS, fractional shortening.

Mortality rates among patients with $\mathrm{HFrEF}$, patients with HFmrEF, and patients with HFpEF were not significantly different. In disagreement with our results, patients with HFpEF had worse mortality rates than patients with HFrEF. ${ }^{40}$ Patients with HFrEF were reported to improve on treatment and, therefore, achieve a better outcome, whereas patients with HFpEF worsened over time due to progressive myocardial remodeling, progressive systolic dysfunction, and deterioration of the EF. ${ }^{41,42}$ With regards to patients with HFmrEF, conflicting data exist in the literature. ${ }^{43}$ HFmrEF patients may have one of the two courses; either remodeling of the myocardium and progressive reduction of $\mathrm{EF}$, or improvement with therapy as patients with HFrEF. $^{41}$ Such conflicting data may increase the importance of monitoring disease trends in HF, especially in the mid-range group, as improving or decreasing function may play a pivotal role in determining the prognosis in this group of patients. ${ }^{43}$ The differences noted in our study may be either due to the different demographic sample characteristics or due to the low number of in-patient mortalities encountered in our sample.

Upon studying the different echocardiographic findings among different types of HF, higher FS was commonly encountered among patients with HFpEF, whereas higher LVd, LVs, left atrial volume and aortic root dimension were encountered among patients with HFrEF. In the current study, diastolic dysfunction, LVd, and FS were the only significant correlates of the EF on logistic regression analysis. The higher the LVd, the lower the Fs, and the less the diastolic dysfunction, the more likely the EF would be decreased and the patient would have HFrEF. Interestingly, HFmrEF patients did not show echocardiographic signs of left-ventricular dysfunction as in the HFpEF group: their echocardiographic features were similar to HFrEF patients, which may indicate that those patients might be of the phenotype who would improve on a long-term basis with treatment. There was no significant difference between HFmrEF 
Table 3 Ordinal Logistic Regression of Clinical and Echocardiographic Correlates of Ejection Fraction

\begin{tabular}{|c|c|c|c|c|c|c|}
\hline Predictor & B & SE & $95 \% \mathrm{Cl}$ & $\chi^{2}$ & OR & $p$ \\
\hline Sex (Male) & 0.01 & 0.15 & {$[-0.30,0.29]$} & 0.00 & 1.01 & 0.973 \\
\hline Nationality (None-Saudi) & -0.12 & 0.14 & {$[-0.15,0.38]$} & 0.75 & 0.89 & 0.387 \\
\hline In-Hospital mortality (Yes) & -0.36 & 0.32 & {$[-0.27,0.98]$} & 1.23 & 0.70 & 0.267 \\
\hline LVd & -0.99 & 0.13 & {$[0.75,1.24]$} & 62.66 & 0.37 & $<.001$ \\
\hline LVs & 0.00 & 0.00 & {$[-0.00,0.00]$} & 0.04 & 1.00 & 0.839 \\
\hline FS & 0.16 & 0.01 & {$[-0.17,-0.14]$} & 292.69 & 1.17 & $<.001$ \\
\hline Left Atrium & 0.01 & 0.06 & {$[-0.13,0.11]$} & 0.04 & 1.01 & 0.845 \\
\hline Aortic Root & -0.02 & 0.17 & {$[-0.32,0.36]$} & 0.01 & 0.98 & 0.903 \\
\hline Diastolic Dysfunction (Yes) & 1.05 & 0.24 & {$[-1.52,-0.58]$} & 19.00 & 2.86 & $<.001$ \\
\hline
\end{tabular}

Abbreviations: B, standardized coefficient; FS, fractional shortening; LVd, left-ventricular diastolic volume; LVs, left ventricular systolic volume; SE, standard error of the estimate; OR, odd's ratio; $X^{2}$, chi-square.

and HFrEF in terms of left-ventricular dysfunction and wall changes, and ventricular dysfunction was significantly more common in HFpEF patients.

The strengths of this study are that it is, to the best of our knowledge, the first study to describe echocardiographic findings in patients with HF in Saudi Arabia; and that it was conducted on a large sample. One of the limitations of our study is that we could not track the patients longitudinally to track any changes in the EF in the future. Another limitation was that the mortality rates calculated were only the in-patient mortality, not the overall mortality because a significant proportion of the patients could not be reached after discharge. Additionally, risk factors for HF (eg hypertension, smoking, diabetes, coronary artery disease, cardiomyopathy, etc.) were not included in our study. These limitations should be considered in future research.

\section{Conclusion}

Females with HF in Saudi Arabia were more likely to have HFpEF, whereas males were more likely to have HFmrEF or HFrEF. In-hospital mortality rates were comparable

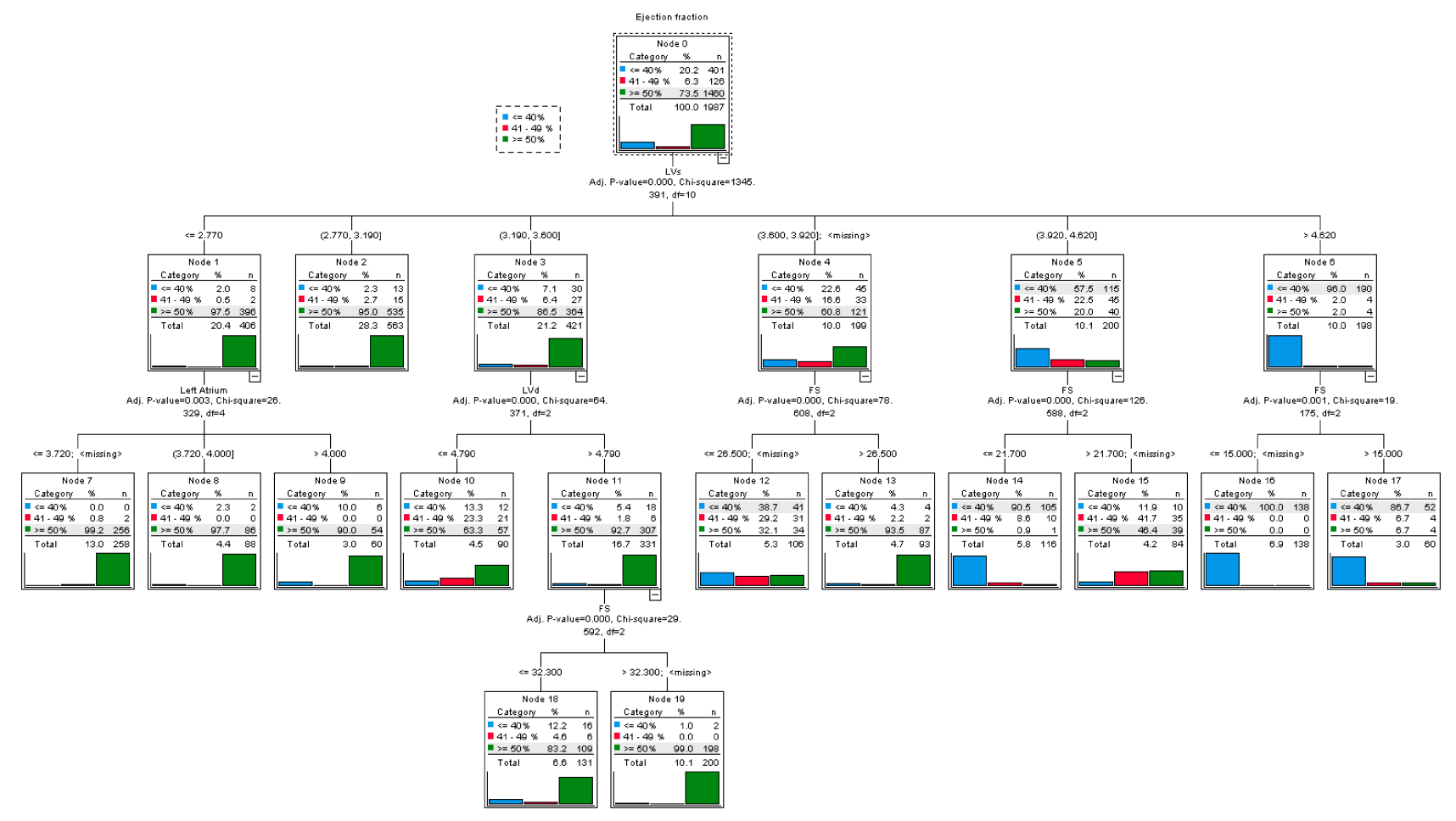

Figure 2 Tree diagram for ejection fraction with nationality, sex, in-hospital mortality, LVd, LVs, FS, left atrium volume, aortic root dimension, and diastolic dysfunction. Abbreviations: LVd, left-ventricular diastolic volume; LVs, left ventricular systolic volume; FS, fractional shortening. 
between the three types of HF. FS was common among patients with $\mathrm{HFpEF}$, whilst LVd, LVs, left atrium volume and aortic root dimensions were higher among patients with HFrEF. Knowledge about the echocardiographic findings among patients with HF in Saudi Arabia can provide a clue about the etiologies, risk factors, prognosis, and management plans required for those patients in the country, and therefore, assist in establishing appropriate preventive and therapeutic strategies for disease management.

\section{Disclosure}

The authors report no conflicts of interest in this work.

\section{References}

1. Benjamin EJ, Muntner P, Alonso A, et al. Heart disease and stroke statistics-2019 update: a report from the American heart association. Circulation. 2019;139(10): e56-528.

2. Amsallem M, Kuznetsova T, Hanneman K, Denault A, Haddad F. Right heart imaging in patients with heart failure: a tale of two ventricles. Curr Opin Cardiol. 2016;31(5):469-482. doi:10.1097/ HCO.0000000000000315

3. Doherty JU, Kort S, Mehran R, Schoenhagen P, Soman P. ACC/AATS/ AHA/ASE/ASNC/HRS/SCAI/SCCT/SCMR/STS 2017 appropriate use criteria for multimodality imaging in valvular heart disease: a report of the american college of cardiology appropriate use criteria task force, American Association for thoracic surgery. J Am Coll Cardiol. 2017;70 (13):1647-1672. doi:10.1016/j.jacc.2017.07.732

4. Andersen OS, Smiseth OA, Dokainish H, et al. Estimating left ventricular filling pressure by echocardiography. $\mathrm{J} \mathrm{Am} \mathrm{Coll} \mathrm{Cardiol}$. 2017;69(15):1937-1948. doi:10.1016/j.jacc.2017.01.058

5. Krum H, Abraham WT. Heart failure. Lancet. 2009;373(9667):941955. doi:10.1016/S0140-6736(09)60236-1

6. Tanai E, Frantz S. Pathophysiology of heart failure. Compr Physiol. 2016;6(1):187-214.

7. Inamdar A, Inamdar A. Heart failure: diagnosis, management and utilization. J Clin Med. 2016;5(7):62. doi:10.3390/jcm5070062

8. Garg V, Vorobiof G. Echocardiography and alternative cardiac imaging strategies for long-term cardiotoxicity surveillance of cancer survivors treated with chemotherapy and/or radiation exposure. Curr Oncol Rep. 2016;18(8). doi:10.1007/s11912-016-0532-y

9. Chang AM, Maisel AS, Hollander JE. Diagnosis of heart failure. Heart Fail Clin. 2009;5(1):25-35. doi:10.1016/j.hfc.2008.08.013

10. King M, Kingery J, Casey B. Diagnosis and evaluation of heart failure. Am Fam Physician. 2012;85(12):1161-1168.

11. Marwick TH, Gillebert TC, Aurigemma G, et al. Recommendations on the use of echocardiography in adult hypertension: a report from the European Association of Cardiovascular Imaging (EACVI) and the American Society of Echocardiography (ASE) †. Eur Heart $J$ Cardiovasc Imaging. 2015;16(6):577-605. doi:10.1093/ehjci/jev076

12. Nagueh SF, Smiseth OA, Appleton CP, et al. Recommendations for the evaluation of left ventricular diastolic function by echocardiography: an update from the American society of echocardiography and the European Association of cardiovascular imaging. $J \mathrm{Am}$ Soc Echocardiogr. 2016;29(4):277-314. doi:10.1016/j.echo.2016.01.011

13. Marwick TH. The role of echocardiography in heart failure. J Nucl Med. 2015;56(Supplement_4):31S-38S. doi:10.2967/jnumed.114.150433

14. Subki AH, Mortada HH, Alsallum MS, et al. Basic life support knowledge among a nonmedical population in Jeddah, Saudi Arabia: cross-sectional study. Interact J Med Res. 2018;7(2): e10428. doi: $10.2196 / 10428$
15. Qara FJ, Alsulimani LK, Fakeeh MM, Bokhary DH. Knowledge of nonmedical individuals about cardiopulmonary resuscitation in case of cardiac arrest: a cross-sectional study in the population of Jeddah, Saudi Arabia. Emerg Med Int. 2019;2019:1-11. doi:10.1155/2019/3686202

16. Al-Shamiri MQ. Heart failure in the Middle East. Curr Cardiol Rev. 2013;9(2):174-178. doi:10.2174/1573403X11309020009

17. AlHabeeb W, Akhras K, AlGhalayini K, et al. Understanding heart failure burden in Middle East countries: economic impact in Egypt, Saudi Arabia and United Arab Emirates. Value Health. 2018;21: S123. doi:10.1016/j.jval.2018.04.840

18. AbuRuz ME, Alaloul F, Saifan A, Masa'deh R, Abusalem S. Quality of life for Saudi patients with heart failure: a cross-sectional correlational study. Glob J Health Sci. 2015;8(3):49. doi:10.5539/gjhs. v8n3p49

19. AlHabeeb W, Al-Ayoubi F, AlGhalayini K, et al. Saudi Heart Association (SHA) guidelines for the management of heart failure. J Saudi Heart Assoc. 2019;31(4):204-253. doi:10.1016/j.jsha.2019.06.004

20. Almalki MA, AlJishi MN, Khayat MA, et al. Population awareness of coronary artery disease risk factors in Jeddah, Saudi Arabia: a cross-sectional study. Int J Gen Med. 2019;12:63-70. doi:10.2147/ IJGM.S184732.

21. Elasfar A, AlShaghaa W, Abdulaal M. Frequency of risk factors and aetiologies for heart failure in Saudi Arabia: a hospital-based study. Egypt Heart J. 2014;66(1):12. doi:10.1016/j.ehj.2013.12.034

22. Ho KKL, Pinsky JL, Kannel WB, Levy D. The epidemiology of heart failure: the Framingham study. J Am Coll Cardiol. 1993;22(4):A6A13. doi:10.1016/0735-1097(93)90455-A

23. Prior D, Coller J. Echocardiography in heart failure: a guide for general practice. Aust Fam Physician. 2010;39(12):904-909.

24. William E.W. Using IBM ${ }^{\circledR}$ SPSS $^{\circledR}$ Statistics for Research Methods and Social Science Statistics. Fourth. SAGE Open; 2013.

25. Kirkpatrick LAFB. A Simple Guide to IBM SPSS Statistics for Version 20.0. Student ed. Belmont, Calif: Wadsworth, Cengage Learning; 2013.

26. Louviere JJ, Hensher DA, Swait JD, Adamowicz W. Combining sources of preference data. In: Stated Choice Methods. 2010:227-251.

27. Mesquita ET, Barbetta LMDS, Correia ETDO, de O. Heart failure with mid-range ejection fraction - state of the art. Arq Bras Cardiol. 2019;112(6):784-790. doi:10.5935/abc.20190079

28. Ponikowski P, Voors AA, Anker SD, et al. 2016 ESC guidelines for the diagnosis and treatment of acute and chronic heart failure: the task force for the diagnosis and treatment of acute and chronic heart failure of the European Society of Cardiology (ESC). Developed with the special contribution. Eur J Heart Fail. 2016;18(8):891-975.

29. Doughty RN, Cubbon R, Ezekowitz J, et al. The survival of patients with heart failure with preserved or reduced left ventricular ejection fraction: an individual patient data meta-analysis: meta-analysis Global Group in Chronic Heart Failure (MAGGIC). Eur Heart $J$. 2013;33(14):1750-1757.

30. Mashat AA, Subki AH, Bakhaider MA, et al. Atrial fibrillation: risk factors and comorbidities in a tertiary center in Jeddah, Saudi Arabia. Int J Gen Med. 2019;12:71-77. doi:10.2147/IJGM.S188524

31. Subki AH, Bakhaidar MG, Bakhaider MA, et al. Trends in mitral valve prolapse: a tertiary care center experience in Jeddah, Saudi Arabia. Int J Gen Med. 2019;12:55-61. doi:10.2147/IJGM.S177635

32. Tromp J, MacDonald MR, Ting Tay W, et al. Heart failure with preserved ejection fraction in the young. Circulation. 2018;138 (24):2763-2773. doi:10.1161/CIRCULATIONAHA.118.034720

33. Cheng RK, Cox M, Neely ML, et al. Outcomes in patients with heart failure with preserved, borderline, and reduced ejection fraction in the Medicare population. Am Heart J. 2014;168(5):721-730.e3. doi:10.1016/j.ahj.2014.07.008

34. Allen LA, Magid DJ, Gurwitz JH, et al. Risk factors for adverse outcomes by left ventricular ejection fraction in a contemporary heart failure population. Circ Heart Fail. 2013;6(4):635-646. doi:10.1161/ CIRCHEARTFAILURE. 112.000180 
35. Del Buono MG, Buckley L, Abbate A. Primary and secondary diastolic dysfunction in heart failure with preserved ejection fraction. Am J Cardiol. 2018;122(9):1578-1587. doi:10.1016/j.amjcard.20 18.07.012

36. Redfield MM. Heart failure with preserved ejection fraction. $N$ Engl J Med. 2016;375(19):1868-1877. doi:10.1056/NEJMcp1511175

37. Borlaug BA. The pathophysiology of heart failure with preserved ejection fraction. Nat Rev Cardiol. 2014;11(9):507-515. doi:10.1038/ nrcardio. 2014.83

38. Dunlay SM, Roger VL, Weston SA, Jiang R, Redfield MM. Longitudinal changes in ejection fraction in heart failure patients with preserved and reduced ejection fraction. Circ Heart Fail. 2012;5(6):720-726. doi:10.1161/CIRCHEARTFAILURE.111.966 366

39. Simmonds SJ, Cuijpers I, Heymans S, Jones EAV. Cellular and molecular differences between HFpEF and HFrEF: a step ahead in an improved pathological understanding. Cells. 2020;9(1):242. doi:10.3390/cells9010242
40. Metra M, Nodari S, Parrinello G, Giubbini R, Manca C, Dei Cas L. Marked improvement in left ventricular ejection fraction during longterm $\beta$-blockade in patients with chronic heart failure: clinical correlates and prognostic significance. Am Heart J. 2003;145(2):292-299. doi:10.1067/mhj.2003.105

41. Basuray A, French B, Ky B, et al. Heart failure with recovered ejection fraction clinical description, biomarkers, and outcomes. Circulation. 2014;129(23):2380-2387. doi:10.1161/CIRCULATIONAHA.113.006 855

42. Kraigher-Krainer E, Shah AM, Gupta DK, et al. Impaired systolic function by strain imaging in heart failure with preserved ejection fraction. J Am Coll Cardiol. 2014;63(5):447-456. doi:10.1016/j. jacc.2013.09.052

43. Farré N, Lupon J, Roig E, et al. Clinical characteristics, one-year change in ejection fraction and long-term outcomes in patients with heart failure with mid-range ejection fraction: a multicentre prospective observational study in Catalonia (Spain). BMJ Open. 2017;7(12): e018719. doi:10.1136/bmjopen-2017-018719

\section{Publish your work in this journal}

The International Journal of General Medicine is an international, peer-reviewed open-access journal that focuses on general and internal medicine, pathogenesis, epidemiology, diagnosis, monitoring and treatment protocols. The journal is characterized by the rapid reporting of reviews, original research and clinical studies across all disease areas. The manuscript management system is completely online and includes a very quick and fair peer-review system, which is all easy to use. Visit http://www.dovepress.com/ testimonials.php to read real quotes from published authors. 